\title{
Relation between similar aftershocks and ruptured asperity of a large inland earthquake: Example of the 2007 Noto Hanto earthquake
}

\author{
Yoshihiro Hiramatsu ${ }^{1}$, Misaki Hayashi ${ }^{2}$, Aiko Hayashi ${ }^{3}$, and the group for \\ the joint aftershock observations of the 2007 Noto Hanto Earthquake \\ ${ }^{1}$ School of Natural System, College of Science and Engineering, Kanazawa University, Kakuma, Kanazawa, Ishikawa 920-1192, Japan \\ ${ }^{2}$ Graduate School of Natural Science and Technology, Kanazawa University, Kakuma, Kanazawa, Ishikawa 920-1192, Japan \\ ${ }^{3}$ Department of Earth Sciences, Faculty of Science, Kanazawa University, Kakuma, Kanazawa, Ishikawa 920-1192, Japan
}

(Received July 16, 2010; Revised November 22, 2010; Accepted November 24, 2010; Online published February 28, 2011)

\begin{abstract}
We investigate spatial distribution of similar aftershocks of a large inland earthquake using waveform data obtained by a dense temporary seismic network. Similar earthquakes on the source fault are mainly located around the deeper edge of the major asperity. The cumulative slip estimated from the similar earthquakes ranges from 0.6 to $2.7 \mathrm{~cm}$ and coincides with the slip estimated from postseismic crustal movement observed by GPS. The slip velocity estimated from both the slip and the recurrence interval of the similar earthquakes is larger at the edge of the asperity. These results suggest that the afterslip area is spatially complementary to the asperity on the fault surface for inland earthquakes similar to large interplate earthquakes on the plate interface.
\end{abstract}

Key words: Similar earthquake, asperity, afterslip, inland earthquake, the 2007 Noto Hanto earthquake.

\section{Introduction}

Frictional properties control the slip behavior, such as seismic slip and aseismic slip, on a fault surface. Asperity, as a seismic slip area, is characterized by a strong coupling in the interseismic period and a large coseismic slip (e.g. Lay et al., 1982). On the other hand, steady slip or afterslip occurs in the aseismic slip area around the asperity in the interseismic and postseismic periods (e.g. Yagi and Kikuchi, 2003). Afterslip is observed geodetically after a large earthquake (e.g. Heki et al., 1997). If the afterslip area includes small asperities, repeating ruptures of each asperity can generate similar earthquakes due to the stress accumulation caused by the afterslip. We can, therefore, obtain information on afterslip using data from similar earthquakes.

The 2007 Noto Hanto earthquake ( $M_{\text {JMA }} 6.9$ ) occurred at 9:41 (JST) March 25, 2007 at a depth of $11 \mathrm{~km}$ beneath the west coast of Noto Peninsula, central Japan (Fig. 1). Inversion analyses of geodetic data (e.g. Fukushima et al., 2008) and strong motion data (e.g. Horikawa, 2008) showed that the dominant slip was on a reverse fault with right-lateral slip and that the area of large slip, or asperity, was distributed from the hypocenter to the shallow part of the fault plane. Hashimoto et al. (2008) started GPS observations during the period from 25 to 29 March 2007 and continued these for about 40 days after the earthquake. They reported that the initial postseismic displacement rapidly decayed within 20 days after the occurrence of the mainshock and suggested a nearly pure right-lateral afterslip of less than

Copyright (C) The Society of Geomagnetism and Earth, Planetary and Space Sciences (SGEPSS); The Seismological Society of Japan; The Volcanological Society of Japan; The Geodetic Society of Japan; The Japanese Society for Planetary Sciences; TERRAPUB.

doi: $10.5047 /$ eps.2010.11.010
$5 \mathrm{~cm}$ on the shallow portion of the source fault based on inversion of postseismic displacements with the variable slip model.

If spatial distribution of the frictional parameters controls slip behavior on the fault, the asperity area and the afterslip area are expected to be spatially complementary. We cannot, however, find such a relationship between spatial distribution of the coseismic slip (Horikawa, 2008) and that of the afterslip (Hashimoto et al., 2008) for the 2007 Noto Hanto earthquake. One of the reasons why no relationship is found is a poor spatial resolution of the afterslip distribution of the 2007 Noto Hanto earthquake. An investigation of afterslip using data from similar earthquakes overcomes this weakness because spatial resolution of the aftershock hypocenters is much higher than that of the afterslip analyzed geodetically.

Within 4 days after the mainshock, the group for the joint aftershock observation of the 2007 Noto Hanto Earthquake installed most of temporary seismic stations around the source region to obtain detailed information on the distribution of aftershocks and seismic activity for about 2 months (Sakai et al., 2007). Sakai et al. (2008) relocated 1318 aftershocks with magnitudes larger than 1.8 listed in the Japan Meteorological Agency catalogue for the period from March 25 to April 18, 2007 using dense network data. They showed that aftershocks formed a well-defined southeastdipping plane and that the shallower extension of the fault plane coincided with the active faults on sea floor reported by Katagawa et al. (2005).

Most aftershocks are usually distributed around the large slip area of the mainshock (Mendoza and Hartzell, 1988). The aftershocks of the 2007 Noto Hanto earthquake are, however, distributed not only around the large asperity but also on the asperity (e.g. Horikawa, 2008), providing a good 

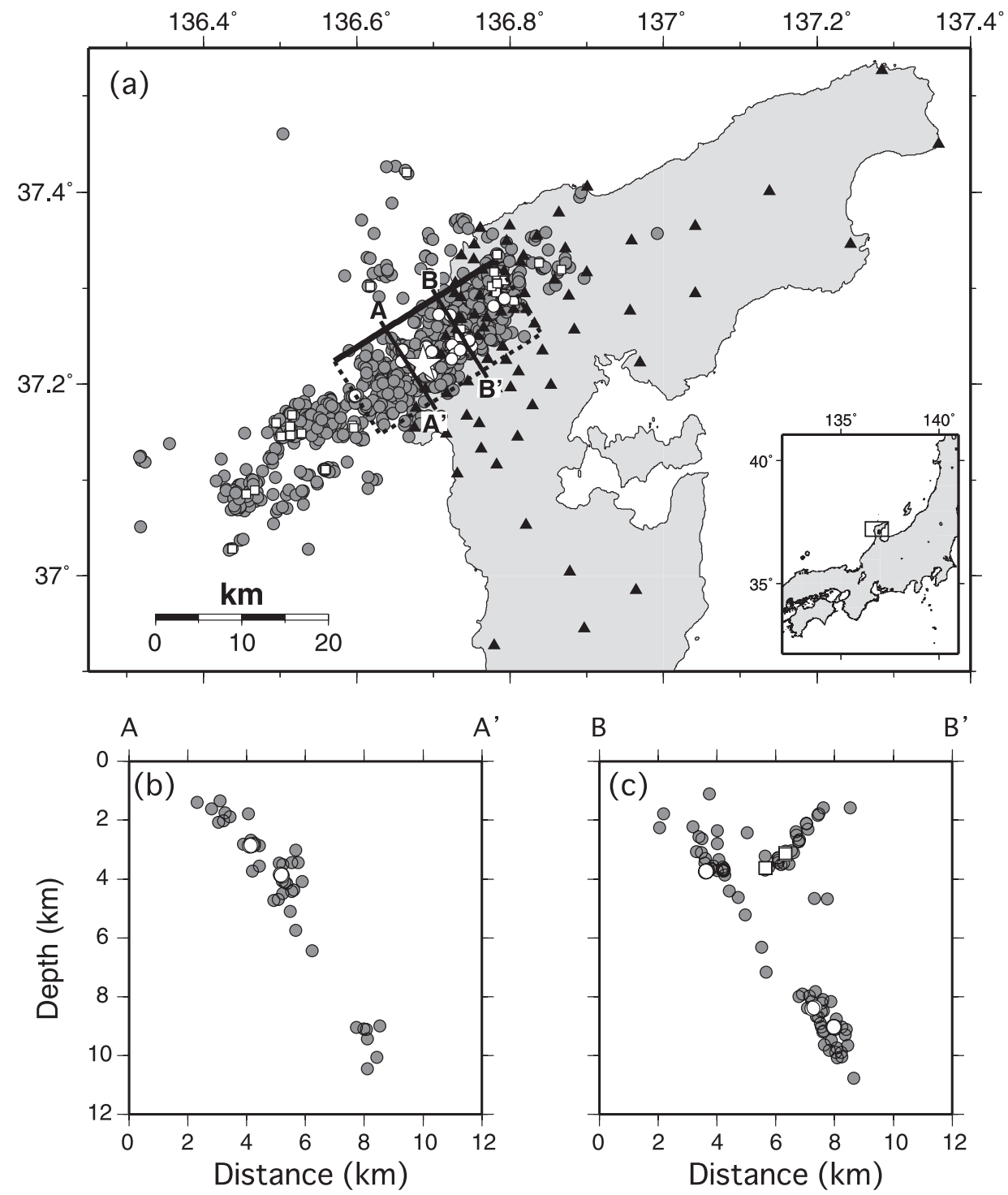

Fig. 1. (a) The distribution of the epicenters of the mainshock (star) and the aftershocks from March 25 to April 18, 2007 (gray circles) of the 2007 Noto Hanto earthquake and similar earthquakes on the source fault (open circles), those not on the source fault (open squares), and the seismic stations (triangles). The dotted rectangle with the solid line as the upper edge indicates the location of the source fault of Horikawa (2008). Lines show the location of the profiles in (b) and (c). Vertical distributions of the similar earthquakes and the aftershocks within 1-km width of (b) the profile A-A' and (c) the profile B-B'.

opportunity to reveal the spatial relationship among the asperity, the similar earthquakes, and the afterslip areas. Here, we investigate detailed distribution of similar earthquakes in the aftershocks of the 2007 Noto Hanto earthquake using data obtained by the group making aftershock observations of the 2007 Noto Hanto earthquake. We also present the distribution of the slip velocity inferred from both the time interval between the successive two earthquakes of each group and the slip of the latter event.

\section{Data and Method}

We use the waveform data recorded at both permanent stations and the temporary stations shown in Fig. 1. These data are the same as those of Sakai et al. (2008). We use $P$-wave velocity structure and station corrections provided by Sakai et al. (2008) and $V_{P} / V_{S}=1.73$ for relocation of the hypocenters.

First, we select pairs of aftershocks whose cross correla- tion coefficients in a $10-\mathrm{s}$ time window of $1-$ to $4-\mathrm{Hz}$ bandpass filtered waveforms are greater than 0.95 at more than 5 stations. The time window starts $0.3 \mathrm{~s}$ prior to the $P$ wave arrival, and the $S$-wave is included within the 10 -s time window. We divide these events into 89 groups by linking the cross-correlation coefficients. That is, if several pairs of aftershocks are connected by the same event, we classify them as one group (Igarashi et al., 2003). We reexamine the arrival times of $P$ - and $S$-waves and the maximum amplitude of these earthquakes using the WIN system (Urabe and Tsukada, 1991) and determine their hypocenters using the hypomh (Hirata and Matsu'ura, 1987) with the station corrections of Sakai et al. (2008). Second, we calculate the precise travel time difference of $P$ - and $S$ waves from the cross spectrum at $1-$ to $8-\mathrm{Hz}$ frequency bands at which the root mean square of coherency is greater than 0.8 (Ito, 1985). We then apply the double-difference method (Waldhauser and Ellsworth, 2000) to relocate the 


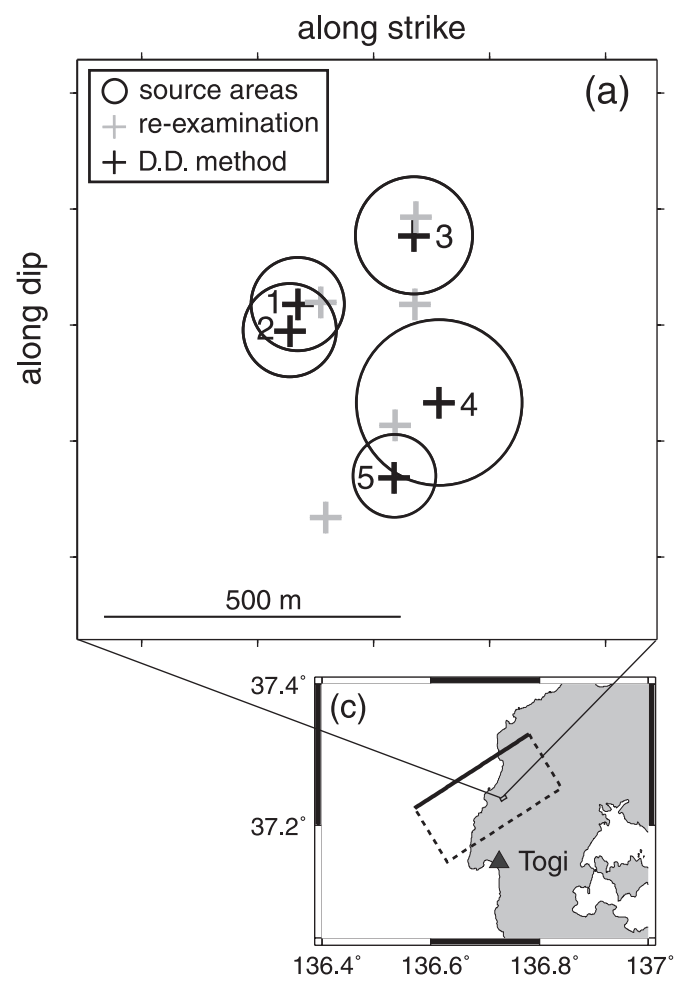

(b) Vertical component at Togi station (BPF : $1-8 \mathrm{~Hz})$
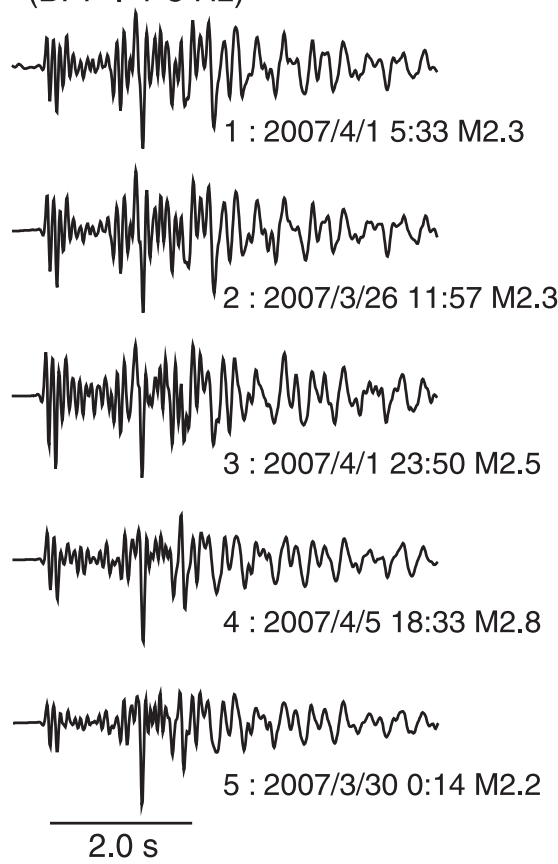

Fig. 2. An example of the analyses of similar earthquakes. (a) The hypocenter distribution of earthquakes reexamined manually (gray pluses) and those determined by the double-difference (D.D) method (black pluses) projected on the fault plane. Circles show the source radius estimated by the circular crack model (Brune, 1970) with a constant stress drop. (b) Band-pass filtered (1-8 Hz) waveforms of the vertical component recorded at the TOGI station. The amplitude of each waveform is normalized to unity. The origin time (JST) and the magnitude are displayed at the bottom right of each waveform. (c) The location of the source fault (dotted rectangle with the solid line as the upper edge) (Horikawa, 2008) and the station TOGI. A small rectangle shows the area of (a).

earthquakes of each group.

Not only the precise location of hypocenters but also the source dimension is necessary to find similar earthquakes. We estimate the source radius, $r$, of an earthquake from the magnitude, $M$, using a scaling relationship between the scalar moment, $M_{\mathrm{o}}(\mathrm{N} \mathrm{m})$, and the magnitude, $\log M_{\mathrm{o}}=$ $1.5 M+9.1$, and the circular fault model of Brune (1970), $\Delta \sigma=7 M_{\mathrm{o}} / 16 r^{3}$. For recent inland large earthquakes in Japan, the 2000 western Tottori earthquake (Ito, 2005), and the 2005 west off Fukuoka prefecture earthquake (Iio et al., 2006), the average static stress drop of aftershock is about $3 \mathrm{MPa}$. We thus assume that a constant stress drop, $\Delta \sigma$, of $3 \mathrm{MPa}$ in this study. Asano and Iwata (2010) recently reported that, for the coseismic slip of the 2007 Noto Hanto earthquake, the average static stress drop on the asperities was $9.5 \mathrm{MPa}$ and that off the asperities was $2.5 \mathrm{MPa}$ based on analyses of strong motion data. Our adopted value is not largely different from the average of their results.

Figure 2 shows an example of our analysis of similar earthquakes. First, five events are selected from the crosscorrelation. Events 1 and 2 are selected as similar earthquakes based on precise hypocenter determination by the double-difference method and the overlap of source area. There is no overlap of the source area of events 3 and 4 with those of events 1 and 2, indicating that event 3 and 4 does not belong to the group of the events 1 and 2. Similarly, events 3 and 4 do not belong to the same group. A part of the source area of event 4 overlaps with that of event 5. However, the overlap area is small relative to the entire source area of event 4 . We thus consider that events 4 and 5 are not similar earthquakes. Following this methodology, we select 47 groups of similar earthquakes. The number of similar earthquakes of each group is small, with 43 groups consisting of two events, three groups of three events and one group of four events.

Figure 1(b) and 1(c) shows vertical cross sections of the distribution of the similar earthquakes and the aftershocks projected on a vertical plane perpendicular to the strike. The southeastward dipping plane is the source fault plane. In these figures, some of the similar earthquakes occur on the fault plane, while others do not. Nineteen groups are lying on the fault plane, and 11 groups are on the conjugate fault. Hereafter, we focus on the groups lying on the source fault plane to investigate spatial relationship among the similar earthquakes, the asperity (Horikawa, 2008), and the afterslip (Hashimoto et al., 2008). We use the source fault plane of Horikawa (2008), which has the same area as the aftershock distribution during the first day after the mainshock. Hiramatsu et al. (2008) estimated nearly the same source fault plane as Horikawa (2008) from coseismic crustal movement using the distribution of littoral organisms and GPS data.

We estimate the amount of slip for each group of similar earthquakes from extrapolation of the empirical relationship between the scalar moment, $M_{\mathrm{o}}$ (dyne.cm), and the slip, $d$ (cm), $d=1.56 \times 10^{-7} \times M_{\mathrm{o}}^{1 / 3}$ (Somerville et al., 1999). For similar earthquakes on the plate interface, the empirical relationship proposed by Nadeau and Johnson (1998) 

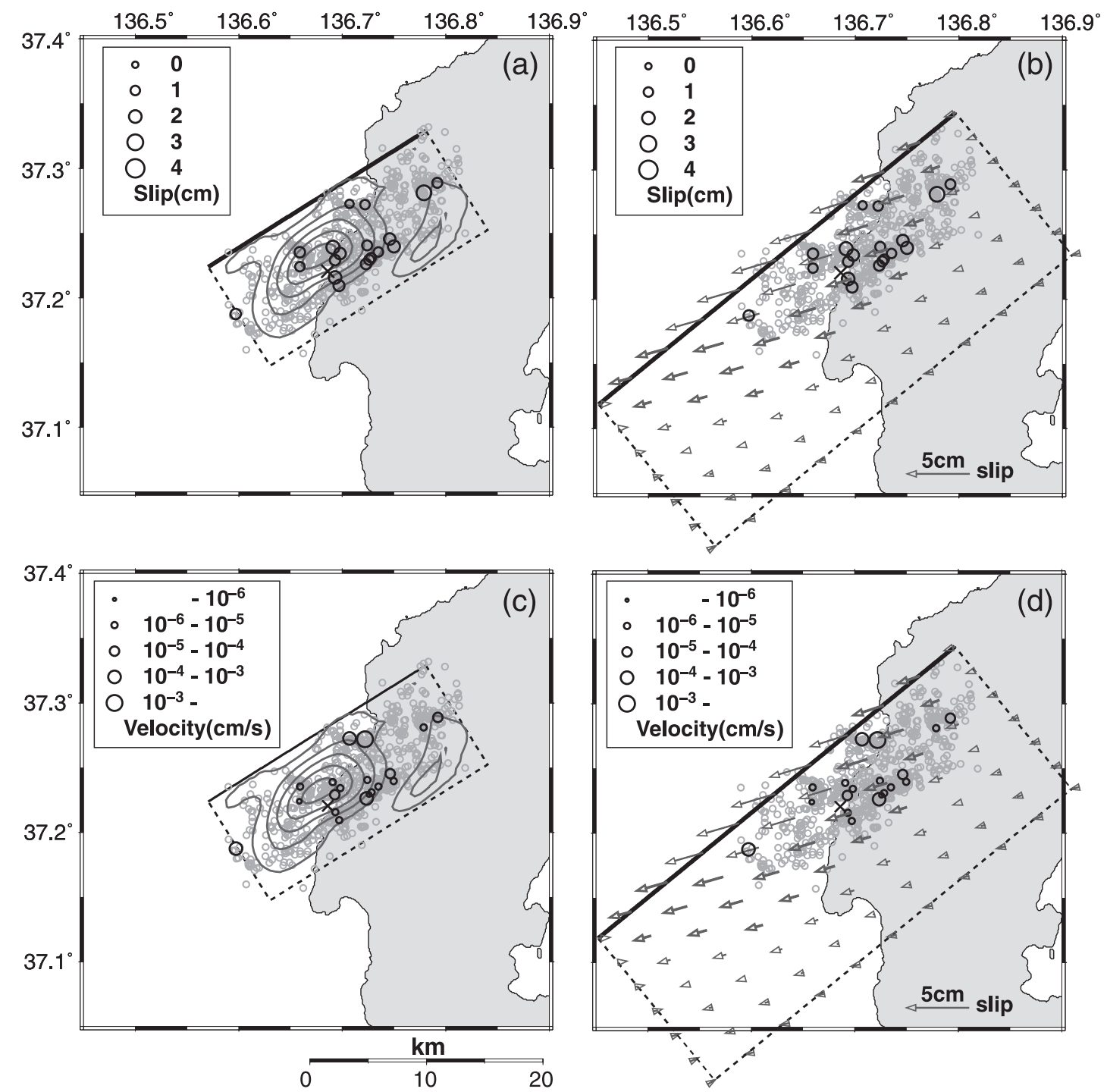

Fig. 3. The distribution of the cumulative slip of the similar earthquakes (black open circles): (a) the coseismic slip (contour lines) (Horikawa, 2008) and (b) the afterslip (Hashimoto et al., 2008): the distribution of the slip velocity estimated from the similar earthquakes (black open circles): (c) the coseismic slip (contour lines) (Horikawa, 2008) and (d) the afterslip (Hashimoto et al., 2008). The contour interval is $0.5 \mathrm{~m}$. Thick arrows show that the amount of the slip ranges 1 to $2 \mathrm{~cm}$. A cross shows the epicenter of the mainshock. Gray circles are the aftershocks from March 25 to April 18 , 2007 on the source fault. Dotted rectangles with the solid line as the upper edge are the fault plane used (a and c) by Horikawa (2008) and (b and d) by Hashimoto et al. (2008).

is generally used to estimate the amount of aseismic slip. However, the relationship of Nadeau and Johnson (1998) produces too large slip, about one order of magnitude larger than both that estimated from the relationship of Somerville et al. (1999) and that of the afterslip estimated by geodetic data (Hashimoto et al., 2008). We thus consider that the relationship of Somerville et al. (1999) is more appopriate to calculate slip in this study.

\section{Results and Discussion}

We use cumulative slip of each group of similar aftershocks as the total slip at the centroid of the group during the analyzed period. The total slip of each group ranges from 0.6 to $2.7 \mathrm{~cm}$ and tends to be large near the deeper edge of the asperity where many similar earthquakes occur (Fig. 3(a)). Figure 3(a) also shows that most of the similar earthquakes are distributed around the deeper edge of the major asperity, indicating that small asperities that cause similar earthquakes are mainly distributed around the asperity. A number of similar earthquakes, however, are distributed on the major asperity, indicating the existence of small asperities inside the major asperities.

We compare the same data with the afterslip distribution estimated from the postseismic crustal movement observed by GPS (Hashimoto et al., 2008) (Fig. 3(b)). The amount of slip estimated from similar earthquakes is coincident with that from the postseismic crustal movement. We find that similar earthquakes do not occur at the shallow part where the largest afterslip is estimated but on the deeper part where the slip of the afterslip ranges from 1 to $2 \mathrm{~cm}$ (Fig. 3(b)). The afterslip distribution from GPS data was estimated with the spatial smoothness constraint, while the slip estimated by similar earthquakes represents the slip in the small areas surrounding the earthquakes. This makes it difficult to distinguish the following two possibilities. The difference between the distribution of the similar 
aftershocks and that of afterslip may mean that there are no small asperities that causes similar aftershocks in the shallow part. The other possibility is that the afterslip is so small in the shallow part of the fault that no similar earthquakes occur.

Next, we estimate the slip velocity from both the time interval between the successive two earthquakes of each group and the slip of the latter event. If a group consists of more than three similar earthquakes, we use the average slip velocity. As shown in Fig. 3(c), we find that the slip velocity tends to be large at the edge of the asperity. However, we find no clear correlation between the slip velocity and the amount of the afterslip (Fig. 3(d)).

The occurrence of similar earthquakes suggests afterslip as a loading process around small asperities. In other words, the afterslip area estimated from the similar earthquakes is spatially complementary to the asperity on the fault surface for the large inland earthquake, similarity to large interplate earthquakes (e.g. Yagi and Kikuchi, 2003).

\section{Conclusions}

We here investigated the spatial relationship between the asperity and the similar aftershocks of an inland earthquake from analyses of a dense temporary seismic network data. The similar earthquakes on the source fault are distributed mainly around the deeper edge of the asperity. The amount of slip of the similar earthquakes, based on an empirical scaling relationship, coincides with that estimated from the postseismic crustal motion observed by GPS. The calculated slip velocity from both the recurrence interval of the successive similar earthquakes and the slip of the latter event is larger at the edge of the asperity. A complementary distribution of the asperity and the similar earthquakes on the source fault suggests that afterslip occurs around or outside the asperity.

Acknowledgments. We thank the Japanese University Group of the Joint Seismic Observations at NKTZ, Earthquake Research Institute, University of Tokyo, Disaster Prevention Research Institute, Kyoto University, Japan Meteorological Agency, and National Research Institute for Earth Science and Disaster Prevention for providing the waveform data. We are grateful to Haruo Horikawa and Manabu Hashimoto for providing their results. Comments from Toru Matsuzawa, Tatsuhiko Hara, and an anonymous reviewer are useful to improve the manuscript. All figures are made using the GMT software (Wessel and Smith, 1998).

\section{References}

Asano, K. and T. Iwata, Characterization of stress drop on asperities estimated from the heterogeneous kinematic slip model for strong motion prediction for inland crustal earthquakes in Japan, Pure Appl. Geophys., doi:10.1007/s00024-010-0116-y, 2010.

Brune, J. N., Tectonic stress and the spectra of seismic shear waves from earthquakes, J. Geophys. Res., 75, 4997-5009, 1970.

Fukushima, Y., T. Ozawa, and M. Hashimoto, Fault model of the 2007 Noto Hanto earthquake estimated from PALSAR radar interferometry and GPS data, Earth Planets Space, 60, 99-104, 2008.

Hashimoto, M., H. Takahashi, R. Doke, M. Kasahara, A. Takeuchi, K. Onoue, Y. Hoso, Y. Fukushima, K. Nakamura, F. Ohya, R. Honda, M. Ichiyanagi, T. Yamaguchi, T. Maeda, and Y. Hiramatsu, Postseismic displacements following the 2007 Noto peninsula earthquake detected by dense GPS observation, Earth Planets Space, 60, 139-144, 2008.

Heki, K., S. Miyazaki, and H. Tsuji, Silent fault slip following an interplate thrust earthquake at the Japan Trench, Nature, 386, 595-598, 1997.

Hiramatsu, Y., K. Moriya, T. Kamiya, M. Kato, and T. Nishimura, Fault model of the 2007 Noto Hanto earthquake estimated from coseismic deformation obtained by the distribution of littoral organisms and GPS: Implication for neotectonics in the northwestern Noto Peninsula, Earth Planets Space, 60, 903-913, 2008.

Hirata, N. and M. Matsu'ura, Maximum-likelihood estimation of hypocenter with origin time eliminated using nonlinear inversion technique, Phys. Earth Planet. Inter., 47, 60-61, 1987.

Horikawa, H., Characterization of the 2007 Noto Hanto, Japan, earthquake, Earth Planets Space, 60, 1017-1022, 2008.

Igarashi, T., T. Matsuzawa, and A. Hasegawa, Repeating earthquakes and interplate aseismic slip in the northeastern Japan subduction zone, $J$. Geophys. Res., 108(B5), 2249, doi:10.1029/2002JB001920, 2003.

Iio, Y., H. Katao, T. Ueno, B. Enescu, N. Hirano, T. Okada, N. Uchida, S. Matsumoto, T. Matsushima, K. Uehira, and H. Shimizu, Spatial distribution of static stress drops for aftershocks of the 2005 west off Fukuoka prefecture earthquake, Earth Planets Space, 58, 1611-1615, 2006.

Ito, A., High resolution relative hypocenters of similar earthquakes by cross spectral analysis method, J. Phys. Earth, 33, 279-294, 1985.

Ito, Y., Mechanisms of aftershock generation, Report of the National Research Institute for Earth Science and Disaster Prevention, 68, 27-89, 2005 (in Japanese with English abstract).

Katagawa, H., M. Hamada, S. Yoshida, H. Kadosawa, A. Mitsuhashi, Y. Kono, and Y. Kinugasa, Geological development of the west sea area of the Noto Peninsula district in the Neogene Tertiary to Quaternary, central Japan, J. Geogr., 114, 791-810, 2005 (in Japanese with English abstract).

Lay, T., H. Kanamori, and L. Ruff, The asperity model and the nature of large subduction zone earthquake, Earthq. Predict. Res., 1, 3-71, 1982.

Mendoza, C. and S. H. Hartzell, Aftershock patterns and main shock faulting, Bull. Seismol. Soc. Am., 78, 1438-1449, 1988.

Nadeau, R. M. and L. R. Johnson, Seismological studies at Parkfield VI: Moment release rates and estimates of source parameters for small repeating earthquakes, Bull. Seismol. Soc. Am., 88, 790-814, 1998.

Sakai, S., A. Kato, E. Kurashimo, T. Iidaka, T. Igarashi, N. Hirata, T. Iwasaki, T. Kanazawa, S. Watanabe, T. Haneda, M. Kobayashi, K. Miura, R. Miura, K. Tagami, I. Ogino, M. Saka, A. Watanabe, K. Miyakawa, K. Katsumata, H. Takahashi, M. Kasahara, R. Honda, T. Maeda, M. Ichiyanagi, T. Yamaguchi, M. Kosuga, T. Okada, J. Nakajima, S. Hori, T. Nakayama, K. Nii, A. Hasegawa, T. Kono, S. Suzuki, N. Tsumura, R. Kobayashi, K. Nozaki, Y. Hiramatsu, K. Sugaya, A. Hayashi, T. Hirose, A. Sawada, K. Tanaka, Y. Yamanaka, H. Nnakamichi, T. Okuda, Y. Iio, K. Nishigami, M. Miyazawa, H. Wada, N. Hirano, S. Nakao, H. Katao, S. Ohmi, K. Ito, T. Shibutani, Y. Kano, I. Doi, S. Noda, T. Katagi, Y. Nishitsuji, S. Matsumoto, K. Matsushima, A. Saiga, H. Miyamachi, K. Imanishi, Y. Kuwahara, I. Cho, M. Hoshino, T. Takeda, Y. Asano, Y. Yukutake, T. Ueno, T. Maeda, T. Matsuzawa, S. Sekine, M. Matsubara, and K. Obara, Aftershock observation for the 2007 Noto Hanto Earthquake, Bull. Earthq. Res. Inst. Univ. Tokyo, 82, 225-233, 2007 (in Japanese with English abstract).

Sakai, S., A. Kato, T. Iidaka, T. Iwasaki, E. Kurashimo, T. Igarashi, N. Hirata, T. Kanazawa, and the group for the joint aftershock observation of the 2007 Noto Hanto Earthquake, Highly resolved distribution of aftershocks of the 2007 Noto Hanto Earthquake by a dense seismic observation, Earth Planets Space, 60, 83-88, 2008.

Somerville, P. G., K. Irikura, R. Graves, S. Sawada, D. Wald, N. Abrahamson, Y. Iwasaki, T. Kagawa, N. Smith, and A. Kowada, Characterizing crustal earthquake slip models for the prediction of strong ground motion, Seismol. Res. Lett., 70, 59-80, 1999.

Urabe, T. and S. Tsukada, A workstation-assisted processing system for waveform data from microearthquake networks, Abstracts of Spring Meeting of Seismological Society of Japan, 70, 1991 (in Japanese).

Waldhauser, F. and W. L. Ellsworth, A double-difference earthquake location algorithm: Method and application to the northern Hayward fault, California, Bull. Seismol. Soc. Am., 90, 1353-1368, 2000.

Wessel, P. and W. H. F. Smith, New, improved version of Generic Mapping Tools released, Eos Trans. AGU, 79, 579, 1998.

Yagi, Y. and M. Kikuchi, Partitioning between seismogenic and aseismic slip as highlighted from slow slip events in Hyuga-nada, Japan, Geophys. Res. Lett., 30, doi:10.1029.2002GL015664, 2003.

Y. Hiramatsu (e-mail: yoshizo@hakusan.s.kanazawa-u.ac.jp), M. Hayashi, A. Hayashi, and the group for the joint aftershock observations of the 2007 Noto Hanto Earthquake 